
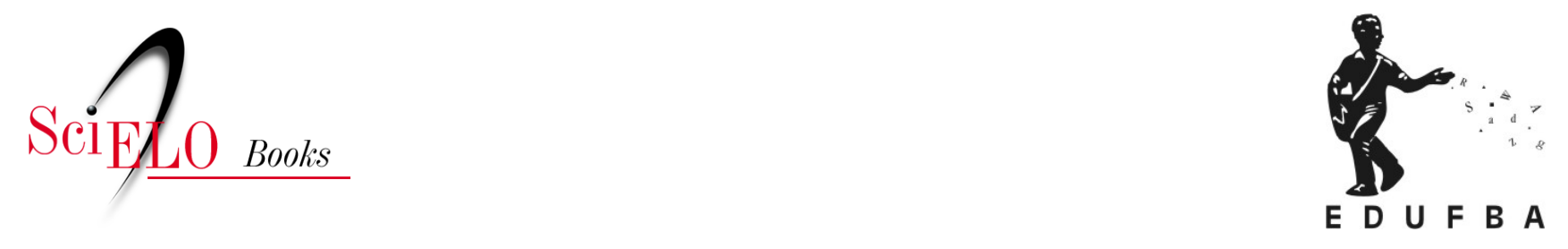

\title{
Estratégias metodológicas adotadas para os cursos em Planejamento e Gestão em Saúde
}

\author{
Mariluce Karla Bomfim de Souza \\ Jussara Cargnin Ferreira
}

SOUZA, M.K.B., and FERREIRA, J.C. Estratégias metodológicas adotadas para os cursos em Planejamento e Gestão em Saúde. In: SOUZA, M.K.B., comp. Planejamento e gestão em saúde: caminhos para o fortalecimento das hemorredes [online]. Salvador: EDUFBA, 2018, pp. 105-124. ISBN 978-85-232-2027-3. https://doi.org/10.7476/9788523220273.0007.

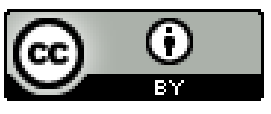

All the contents of this work, except where otherwise noted, is licensed under a Creative Commons Attribution 4.0 International license.

Todo o conteúdo deste trabalho, exceto quando houver ressalva, é publicado sob a licença Creative Commons Atribição 4.0. 


\title{
Estratégias metodológicas adotadas para os cursos em Planejamento e Gestão em Saúde
}

\author{
Mariluce Karla Bomfim de Souza \\ Jussara Cargnin Ferreira
}

\section{Introdução}

A cooperação técnica assumida pelo Instituto de Saúde Coletiva da Universidade Federal da Bahia em resposta à solicitação da Coordenação Geral de Sangue e Hemoderivados do Ministério da Saúde (CGSH/MS) vem desde junho de 2014 cumprindo uma agenda de atividades que parte das reflexões sobre a importância do processo de planejamento até a elaboração de produtos dessa parceria.

Assim, além dos encontros realizados e da oferta dos cursos nas capitais de cinco estados, no ano de 2015, um produto, de natureza pedagógica e instrumental, foi elaborado para o direcionamento do curso e utilização pelos docentes, facilitadores e cursistas. O "Guia para estudos" dos cursos de Atualização em Planejamento e Gestão em Sistemas de Saúde foi elaborado por uma equipe de técnicos da CGSH/MS, gestores de hemorredes estaduais (Minas Gerais, Ceará e Santa Catarina) e três docentes e pesquisadoras do Instituto de Saúde Coletiva, da Universidade Federal da Bahia.

Na sua estrutura, o guia apresenta como elementos pré-textuais uma lista de siglas e uma lista de ícones, esta com o objetivo de sinalizar o leitor e di- 
namizar a leitura a partir de imagens que indicam curiosidades, observações, glossário, estudo de caso, marcador de tempo, vídeos, leituras recomendadas, atividades de dispersão e encerramento de atividades.

Na parte textual, o guia está organizado em duas partes, sendo a primeira dedicada às orientações gerais com descrição dos objetivos e competências esperadas dos cursistas, bem como, dos atores envolvidos e da estrutura e programação dos cursos. Detalhadamente, a descrição sobre estrutura apresenta, sobre os momentos presenciais e os momentos de dispersão, a metodologia, os recursos didáticos e os meios de avaliação do curso.

O desenho dos cursos prevê em seu formato Momentos Presenciais (M1, M2, M3) e Momentos de Dispersão (D1, D2) distribuídos em três ciclos de formação $\left(1^{\circ}, 2^{\circ}\right.$ e $3^{\circ}$ ciclo) que totalizam 92 horas. Para os Momentos Presenciais estão previstas atividades de interação e dinâmica da turma, abordagem dos conteúdos de forma expositiva e dialógica e estudos de caso. Quanto aos Momentos de Dispersão espera-se a aproximação com a prática e a relação com o conteúdo teórico. Tais momentos são intercalados aos momentos presenciais de modo a permitir tal práxis, além de apoiar o desenvolvimento das tarefas de dispersão por meio da orientação sistemática dos facilitadores na plataforma Moodle.

Quadro 1 - Ciclos e respectivos momentos dos Cursos de Planejamento e Gestão em Saúde

\begin{tabular}{|l|l|l|}
\hline 10 CICLO & $\begin{array}{l}\text { Bases para o planejamento nos serviços de } \\
\text { hemoterapia e hematologia no âmbito do Sistema } \\
\text { Único de Saúde. }\end{array}$ & $M 1\left(1^{\circ}\right.$ e $2^{\circ}$ dia); DI \\
\hline 20 CICLO & $\begin{array}{l}\text { Gestão e Planejamento em Saúde: elementos para a } \\
\text { construção do plano como produto. }\end{array}$ & $M 2\left(1^{\circ}\right.$ e $2^{\circ}$ dia); D己 \\
\hline \multirow{2}{*}{ 3o CICLO } & $\begin{array}{l}\text { Sistematização de proposta para o planejamento nos } \\
\text { serviços de hemoterapia e hematologia no âmbito do } \\
\text { SUS. }\end{array}$ & $M 3\left(1^{\circ}\right.$ e $2^{\circ}$ dia $)$ \\
\hline
\end{tabular}

Fonte: Souza e colaboradores (2015).

A metodologia utilizada para o desenvolvimento do curso fundamenta-se na problematização, a qual tem sido proposta como "metodologia de ensino, de estudo e de trabalho", podendo ser entendida como um conjunto de métodos, técnicas, procedimentos ou atividades intencionalmente selecionadas e 
organizadas de acordo com a natureza do problema em estudo e as condições gerais dos participantes. (BERBEL, 1998)

O uso desta metodologia deve partir de um tema, neste caso, o planejamento, de modo que os cursistas olhem atentamente e registrem sistematizadamente sua percepção sobre a parcela da realidade em que aquele tema está sendo vivido. Portanto, parte do princípio de que o cursista é um agente ativo da própria aprendizagem e é capaz de agir intencionalmente para transformar a sua prática, de modo que no compartilhamento das experiências torna-se possível novas reflexões, elaboração de soluções e intervenções em acordo com a demanda da realidade.

Nessa perspectiva, a mediação do processo ensino/aprendizagem é feita pelo docente com o apoio de facilitadores e mediadores, cabendo a estes estimular nos cursistas ${ }^{1}$ a reflexão, pensamento, questionamentos e discussões sobre o planejamento e a Gestão do Sistema e Serviços de Saúde. Tais estímulos e provocações à discussão se dão a partir das abordagens sobre o conteúdo, estudos de caso e leitura da realidade.

O grupo de facilitadores é formado por profissionais da Hemorrede Pública Nacional vinculados à áreas técnicas ou de gestões, com experiência em planejamento, os quais foram preparados para atuar de forma específica no projeto. O grupo de mediadores encontra-se estabelecido de forma a manter o apoio sistemático da CGSH para o desdobramento local das atividades. Assim, para cada Hemorrede Estadual envolvida, além de uma dupla de docentes, conta-se com dois facilitadores e um mediador, sendo este último o elemento que, de forma compartilhada com o ISC, coordena, acompanha e avalia todo o escopo das atividades desenvolvidas.

Sob o formato de "curso" a atualização e, portanto, a capacitação sobre o processo de planejamento e gestão do sistema, e serviços de saúde inclui a abordagem sobre as bases conceituais e teóricas relacionadas ao planejamento no âmbito do SUS. Bem como, os elementos metodológicos para sua aplicação e elaboração do plano como um produto da construção coletiva dos atores envolvidos na sua formulação.

1 A turma de "cursistas" por estado é constituída por gestores e profissionais dos serviços da Hemorrede do respectivo estado, bem como, gestores e técnicos que atuam no sistema de saúde. Conselheiros de saúde também participam dos cursos. 
Para abordagem do conteúdo e programação proposta são utilizadas as seguintes estratégias metodológicas: dinâmica de integração; leitura individual; leitura coletiva; trabalhos de grupo; aulas expositivas dialogadas; estudo de caso. As dinâmicas de integração são propostas com o fim de estimular a participação e expressão dos cursistas sobre a experiência "formativa" em ato; as leituras individuais e coletivas paragrafadas prometem a discussão, o questionamento e o esclarecimento de dúvidas, assim como as aulas expositivas dialogadas; e, os trabalhos de grupo orientados pelo estudo de caso são pretenciosos em provocar no cursista a reflexão sobre uma situação fictícia, mas que remete às situações da realidade e do cotidiano do trabalho de cada cursista, com ênfase na área da Hematologia e Hemoterapia.

Com destaque ao estudo de caso, foi elaborada uma situação hipotética a partir de um estado cunhado como "globulina", para o qual foram desenhados o território estadual, sua divisão regional, a capacidade instalada em serviços de saúde, disponibilidade de leitos e produção de serviços e ações. O estudo de caso foi elaborado e validado pelo grupo de técnicos da CGSH/MS e gestores envolvidos na concepção do Projeto.

Figura 1 - Mapa das macrorregiões de Saúde apresentado no estudo de caso do estado de Globulina

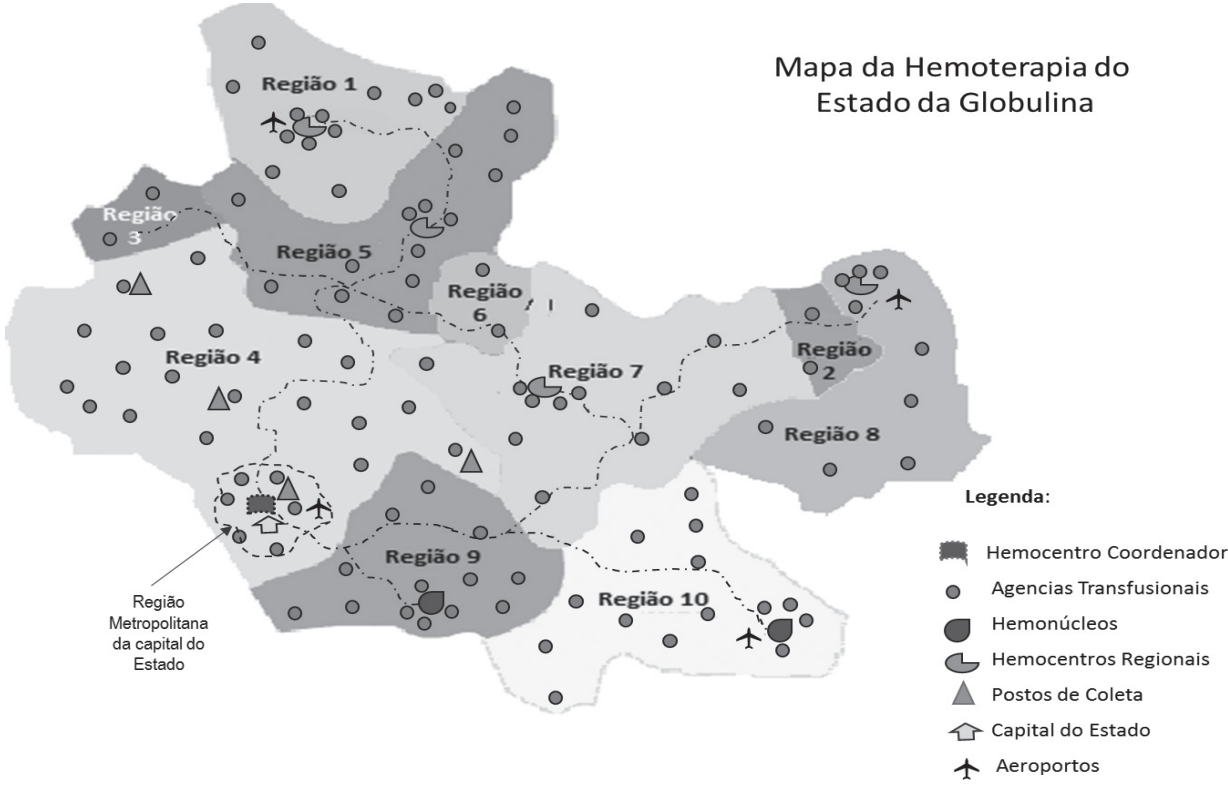

Fonte: Santos e colaboradores (2015). 
O estudo de caso caracteriza-se como um "instrumento pedagógico que apresenta um problema sem solução pré-definida”, exigindo raciocínio crítico e argumentativo dos cursistas para identificá-lo e analisá-lo, bem como desenvolver argumentos lógicos, tomar decisões e propor soluções.

O estudo de caso, bem como, os textos para leitura e atividades propostas estão dispostos no "Guia para estudos", principal recurso didático disponibilizado aos cursistas no primeiro dia (M1) do curso, na versão impressa. Em sua descrição completa, consta como elemento pós-textual do guia, além da extensa lista de referências indicadas e o levantamento da legislação específica da área de sangue e outras normas relacionadas que se constituem como suporte de leitura para o desenvolvimento das atividades propostas.

Também se constitui como elemento pós-textual do guia e de fundamental importância para a análise de situação de saúde, programação e planejamento das hemorredes, os parâmetros para o dimensionamento das necessidades de adequação da rede de serviços de hematologia e hemoterapia, considerando a Portaria $\mathrm{n}^{\circ} 1.631 / 2015$ que recentemente revogou a Portaria $\mathrm{n}^{\circ} 1.101 / 2002$.

O objetivo principal da utilização dos parâmetros é auxiliar os cursistas na direção do conhecimento sobre a rede de serviços hematológicos e hemoterápicos e as suas respectivas necessidades, de forma a compor a análise da situação de saúde do estado. O documento dos parâmetros destaca ainda a importância da exploração das bases de dados populacionais, hemoterápicos e hospitalares para a obtenção das informações desejadas.

Para os momentos de dispersão (D1 e D2), o desenho do curso propõe atividades a serem desenvolvidos in loco, ou seja, nos estados no qual os cursos são ofertados. Assim, visando instrumentalizar o acompanhamento pelos facilitadores, utiliza-se o ambiente virtual - Moodle - o qual funciona como espaço de interação entre cursistas e facilitadores e a orientação e o acompanhamento para a realização das atividades. 
Figura 2 - Página de acesso ao ambiente virtual Moodle do Planeja Sangue

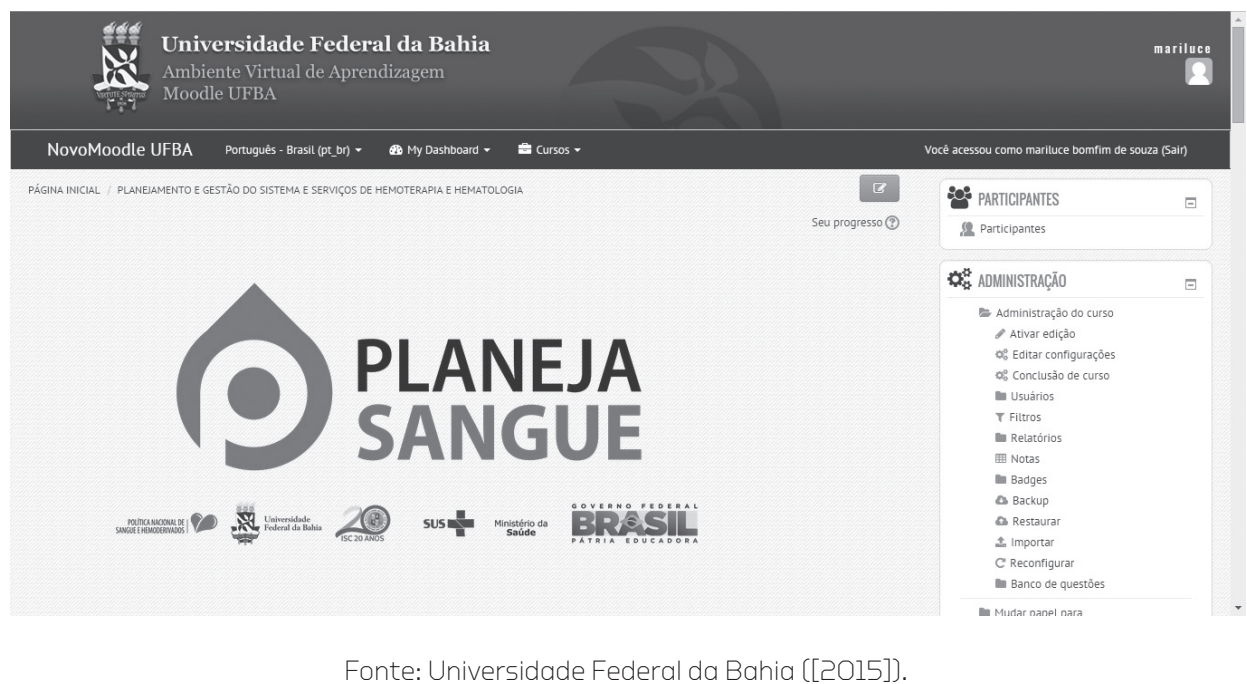

O uso do ambiente virtual está indicado na programação do guia sob o formato de atividades descritas como "Orientação da atividade de dispersão”. Para o desenvolvimento das atividades de dispersão faz-se necessária a utilização do guia, tendo em vista o suporte teórico para a discussão sobre análise de situação de saúde proposta no primeiro momento de dispersão (D1) e o desenho de estratégias de ação para enfrentamento dos principais problemas de saúde relacionados com os serviços de hematologia e hemoterapia da Hemorrede estadual, objetivo a ser alcançado no D2.

Quadro 1 - Objetivos do Momento de Dispersão (D1)

\begin{tabular}{|c|c|}
\hline Objetivo geral & Objetivos específicos \\
\hline \multirow{5}{*}{$\begin{array}{l}\text { Analisar a situação } \\
\text { de saúde da } \\
\text { população e dos } \\
\text { serviços de cada } \\
\text { região do estado. }\end{array}$} & Caracterizar o território estadual por região de abrangência. \\
\hline & $\begin{array}{l}\text { Identificar informações sobre a infraestrutura instalada - recursos humanos; situação } \\
\text { sanitária; sistema de informação; e qualidade. }\end{array}$ \\
\hline & $\begin{array}{l}\text { Descrever a situação da rede de serviços de hemoterapia e hematologia do estado } \\
\text { por região de abrangência - assistência hemoterápica e hematológica (referência/ } \\
\text { contrarreferência), utilizando a matriz de competência dos pontos de atenção. }\end{array}$ \\
\hline & $\begin{array}{l}\text { Identificar informações sobre os dados de produção: consultas, transfusão, capacidade } \\
\text { da imuno-hematologia e sorologia, processamento de hemocomponentes estoque e } \\
\text { distribuição de hemocomponentes, plasma excedente para produção de hemoderivados. }\end{array}$ \\
\hline & $\begin{array}{l}\text { Calcular os parâmetros para dimensionamento das necessidades de adequação da rede de } \\
\text { serviços de hematologia e hemoterapia. }\end{array}$ \\
\hline
\end{tabular}

Fonte: Universidade Federal da Bahia [[2015]]. 
Quadro 2 - Objetivos para o Momento de Dispersão (D2)

\begin{tabular}{|c|c|}
\hline Objetivo geral & Objetivos específicos \\
\hline \multirow{4}{*}{$\begin{array}{l}\text { Desenhar } \\
\text { estratégias de ação } \\
\text { para enfrentamento } \\
\text { dos principais } \\
\text { problemas de } \\
\text { saúde relacionados } \\
\text { com os serviços } \\
\text { de hemoterapia } \\
\text { da Hemorrede } \\
\text { estadual. }\end{array}$} & $\begin{array}{l}\text { Descrever e explicar os principais problemas de saúde identificados a partir da análise de } \\
\text { situação de saúde. }\end{array}$ \\
\hline & Traçar os objetivos considerando os problemas identificados. \\
\hline & Enumerar as operações para o enfrentamento dos problemas. \\
\hline & $\begin{array}{l}\text { Envolver diferentes atores - gestores e técnicos da Hemorrede estadual juntamente com } \\
\text { Vigilância Sanitária, vigilância epidemiológica, planejamento e controle e avaliação - na } \\
\text { discussão sobre os problemas e suas operações de enfrentamento. }\end{array}$ \\
\hline
\end{tabular}

Fonte: Universidade Federal da Bahia ([2015]).

Portanto, diante das atividades presenciais e de dispersão propostas, bem como dos recursos didáticos e metodológicos adotados, tendo em vista os objetivos traçados e as competências esperadas dos cursistas, se exige um acompanhamento e avaliação de todo o processo de desenvolvimento do curso. Nesse sentido, propôs-se a avaliação formativa, entendendo-a como parte integrante do processo de ensino/aprendizagem, ocorrendo durante todo o desenvolvimento do curso, por considerar que o cursista aprende ao longo do processo e reestrutura o seu conhecimento por meio das atividades que executa. Este modo de avaliação tem como finalidade fundamental "a função ajustadora do processo de ensino-aprendizagem para possibilitar que os meios de formação respondam as características dos cursistas". (JORBA; SANMARTÍ, 2003, p. 123) As atividades devem levar os cursistas à reflexão sobre os conteúdos e a aplicação dos conhecimentos gerados, conduzindo-os ao desenvolvimento das competências esperadas.

\section{Apresentação da programação dos cursos: visualizando as atividades propostas}

O “Guia para estudos” apresenta, em sua primeira parte, a programação do curso, indicando o formato em três ciclos de formação, durante os quais são desenvolvidas atividades de aprendizagem distribuídas nos turnos diários com horário programado para cada atividade. A duração de cada atividade é estabelecida como proposta, podendo ser readequada de acordo com as características e o ritmo de trabalho de cada turma. 
As pouco mais de 30 atividades programadas estão descritas detalhadamente no guia, com marcação de tempo, descrição, objetivo e sugestão metodológica para o respectivo desenvolvimento. Ao longo da apresentação das atividades estão incluídos dez textos como base para leitura e discussão, curiosidades com referências de estudiosos, glossários, exercícios e o estudo de caso com questões relacionadas ao tema abordado a fim de estimular a reflexão dos cursistas e provocar a relação teórico-prática. Vale destacar que tais atividades foram validadas em oficina realizada com representantes das hemorredes estaduais brasileiras no mês de abril de 2015, em encontro ocorrido em Salvador, Bahia, Brasil.

Quadro 3 - Programação dos cursos por ciclo segundo horário e identificação e
descrição das atividades propostas no "Guia de estudos"

$1{ }^{\circ} \mathrm{CICLO}$ : BASES PARA O PLANEJAMENTO NOS SERVIÇOS DE HEMOTERAPIA E HEMATOLOGIA NO ÂMBITO DO SISTEMA ÚNICO DE SAÚDE

$1^{\circ} \mathrm{DIA}-\mathrm{MI}$

\begin{tabular}{|c|c|c|}
\hline $\begin{array}{l}\text { Horário } \\
\text { programado }\end{array}$ & Atividades & Descrição \\
\hline \multirow{2}{*}{8 h30 às 9 h30 } & Atividade 1 & Acolhida dos participantes - boas vindas do grupo e dinâmica de integração \\
\hline & Atividade 2 & Apresentação dos objetivos e metodologia do curso \\
\hline $9 h 30$ às llh & Atividade 3 & Exposição dialogada sobre a Situação de Saúde no Brasil \\
\hline llh às $12 \mathrm{~h}$ & Atividade 4 & Trabalho de grupo com plenária interna \\
\hline 13 h30 às 15 h30 & Atividade 5 & $\begin{array}{l}\text { Perguntas e respostas sobre o Sistema Único de Saúde e os Serviços de } \\
\text { Hematologia e Hemoterapia no SUS }\end{array}$ \\
\hline 15 h30 às $16 h 30$ & Atividade 6 & $\begin{array}{l}\text { Leitura coletiva sobre a Situação dos Serviços de Hematologia e } \\
\text { Hemoterapia }\end{array}$ \\
\hline $16 h 30$ às $18 h$ & Atividade 7 & Exposição dialogada sobre Redes de Atenção à Saúde \\
\hline $18 \mathrm{~h}$ às $18 \mathrm{~h} 30$ & Atividade 8 & Avaliação do dia \\
\hline \multicolumn{3}{|r|}{$2^{\circ} \mathrm{DIA}-\mathrm{Ml}$} \\
\hline \multirow{2}{*}{8 h30 às 9 h30 } & \multirow{2}{*}{ Atividade 9} & Acolhida dos participantes - dinâmica de integração \\
\hline & & Apresentação da Estrutura da Hemorrede Estadual \\
\hline $9 h 30$ às $10 h 30$ & Atividade 10 & $\begin{array}{l}\text { Trabalho de grupo - O Sistema de Saúde e a Estrutura Operacional } \\
\text { disponível para o fortalecimento da Hemorrede estadual }\end{array}$ \\
\hline
\end{tabular}




\begin{tabular}{|c|c|c|}
\hline $10 h 30$ às 11 hl5 & Atividade 11 & Plenária interna sobre as atividades 7 e 10 desenvolvidas pelos cursistas \\
\hline 11 lis às l2h & Atividade 12 & $\begin{array}{l}\text { Exposição dialogada sobre o Processo Saúde-doença-cuidado e as } \\
\text { interfaces com a Hemorrede }\end{array}$ \\
\hline $13 \mathrm{~h} 30$ às $15 \mathrm{~h}$ & Atividade 13 & $\begin{array}{l}\text { Exposição dialogada sobre as bases e os aspectos conceituais, } \\
\text { metodológicos, técnicos e práticos do planejamento }\end{array}$ \\
\hline $15 \mathrm{~h}$ às $16 \mathrm{~h}$ & Atividade 14 & $\begin{array}{l}\text { Leitura coletiva sobre os Usos da Epidemiologia para o Planejamento em } \\
\text { Saúde }\end{array}$ \\
\hline 16h às $17 \mathrm{~h}$ & Atividade 15 & $\begin{array}{l}\text { Exposição dialogada sobre os parâmetros para o dimensionamento de } \\
\text { necessidades da Rede de Serviços de Hemoterapia e Hematologia }\end{array}$ \\
\hline 17h às $18 \mathrm{~h} 30$ & Atividade 16 & Orientação da atividade de dispersão \\
\hline \multicolumn{3}{|r|}{ DISPERSÃO - D1 } \\
\hline \multicolumn{3}{|c|}{$\begin{array}{l}2^{\circ} \text { CICLO: GESTÃO E PLANEJAMENTO EM SAÚDE: ELEMENTOS PARA A CONSTRUÇÃO DO PLANO } \\
\text { COMO PRODUTO }\end{array}$} \\
\hline \multicolumn{3}{|r|}{$1^{\circ} \mathrm{DIA}-\mathrm{ML}$} \\
\hline $8 h 30$ às $9 h$ & \multirow{2}{*}{ Atividade 17} & Acolhida dos participantes - dinâmica de integração \\
\hline $9 h$ às $10 h$ & & Resgate da atividade de dispersão \\
\hline lOh às llh & Atividade 18 & Leitura coletiva sobre Planos Diretores \\
\hline llh às leh & \multirow{2}{*}{ Atividade 19} & \multirow{2}{*}{$\begin{array}{l}\text { Trabalho de grupo - identificação/priorização de problemas e elaboração } \\
\text { da programação operativa }\end{array}$} \\
\hline $13 \mathrm{~h} 30$ às $16 \mathrm{~h}$ & & \\
\hline 16h às $18 \mathrm{~h}$ & Atividade 20 & Plenária interna sobre Programação em Saúde \\
\hline 18h às $18 h 30$ & Atividade 21 & Avaliação do dia \\
\hline \multicolumn{3}{|r|}{$2^{\circ} \mathrm{DIA}-\mathrm{M} 2$} \\
\hline 08h30 às 9h & Atividade ટટ & Acolhida dos participantes - dinâmica de integração \\
\hline 9h às $10 h 30$ & Atividade 23 & $\begin{array}{l}\text { Exposição dialogada sobre Trabalho em Equipe e Educação Permanente } \\
\text { em Saúde }\end{array}$ \\
\hline $10 h 30$ às leh & Atividade 24 & $\begin{array}{l}\text { Trabalho de grupo sobre Cultura Organizacional, Liderança e Comunicação } \\
\text { em Saúde }\end{array}$ \\
\hline $13 \mathrm{~h} 30$ às $15 \mathrm{~h}$ & Atividade 25 & Exposição dialogada sobre Tomada de Decisão e Participação em Saúde \\
\hline $15 \mathrm{~h}$ às $16 \mathrm{~h}$ & Atividade 26 & $\begin{array}{l}\text { Leitura individual ou coletiva sobre Planejamento de Investimentos e } \\
\text { Internalização de Planos Diretores }\end{array}$ \\
\hline 16h às 17 h30 & Atividade 27 & $\begin{array}{l}\text { Exposição dialogada sobre Avaliação em Saúde e sua relação com o } \\
\text { Planejamento em Saúde }\end{array}$ \\
\hline $17 \mathrm{~h} 30$ às $18 \mathrm{~h} 30$ & Atividade 28 & Orientação da atividade de dispersão \\
\hline \multicolumn{3}{|r|}{ DISPERSÃO - D2 } \\
\hline
\end{tabular}




\begin{tabular}{|c|c|c|}
\hline \multicolumn{3}{|c|}{$\begin{array}{l}3^{\circ} \mathrm{CICLO} \text { : SISTEMATIZAÇÃO DE PROPOSTA PARA O PLANEJAMENTO NOS SERVIÇOS DE HEMOTERAPIA E } \\
\text { HEMATOLOGIA NO ÂMBITO DO SUS }\end{array}$} \\
\hline \multicolumn{3}{|r|}{$1^{\circ} \mathrm{DIA}-\mathrm{M3}$} \\
\hline 8 h30 às $9 \mathrm{~h}$ & Atividade 29 & Acolhida dos participantes - dinâmica de integraç̃ão \\
\hline $9 h$ às $10 h$ & \multirow{3}{*}{ Atividade 30} & Resgate das atividades de dispersão \\
\hline lOh às li2h & & \multirow{2}{*}{ Oficina de sistematização dos produtos finais } \\
\hline $13 \mathrm{~h} 30$ às $18 \mathrm{~h} 30$ & & \\
\hline \multicolumn{3}{|r|}{$2^{\circ} \mathrm{DIA}-\mathrm{M3}$} \\
\hline 8 h30 às llh & Atividade 31 & Plenária de socialização dos produtos finais \\
\hline llh às leh & Atividade 32 & Avaliação final do Curso \\
\hline
\end{tabular}

Fonte: Souza e colaboradores (2015).

\section{Produto dos cursos de Planejamento e Gestão em Saúde: proposta preliminar do Plano Diretor das hemorredes estaduais}

Desde a concepção do projeto, na condição de "proposta de atualização", a CGSH/MS tinha como expectativa que os cursos proporcionassem aos gestores e técnicos participantes a aprendizagem das bases teóricas e metodológicas para o processo de planejamento e também que subsidiassem a elaboração do Plano Diretor das Hemorredes Estaduais envolvidas.

Nesse sentido, todo o processo de produção, reflexão e discussão do conhecimento sobre planejamento e gestão, além das atividades realizadas com base na realidade de cada estudo serviu para a concretização do desenho preliminar dos planos diretores nos cinco estados em que foram ofertados os cursos no ano de 2015, sendo apresentados em plenária externa, aberta a convidados - gestores, conselheiros, associações, etc - no último dia do curso, durante o M3.

A fim de orientar os cursistas na sistematização das atividades desenvolvidas e das discussões geradas nos momentos presenciais, propôs-se um documento orientador para o desenho da proposta preliminar do Plano Diretor como produto esperado ao final do curso (M3). O documento orientador apresenta inicialmente o plano diretor (I) como um instrumento de gestão e, 
portanto, um elemento norteador do planejamento e das práticas para a organização e operacionalização da assistência hemoterápica e atenção hematológica; em seguida, provoca os cursistas a partir do questionamento sobre a importância de plenária para a socialização dos produtos finais do curso (II), tendo em vista que trata da apresentação do desenho do plano; e, finalmente detalha orientações para a elaboração de um plano diretor com a respectiva proposição de estrutura do documento (III), desde os elementos pré-textuais até os pós-textuais.

\section{I) O que é o Plano Diretor?}

O Plano Diretor é um documento que expressa a política da organização e determina um conjunto de instruções, definidas de forma compartilhada, utilizando-se os meios disponíveis e favoráveis para alcançar seus objetivos, dentro de uma abrangência geográfica delimitada. Portanto, para além dos objetivos, deve explicitar as estratégias e oferecer instrumentos necessários para que os mesmos sejam cumpridos.

Desta forma, o Plano Diretor configura-se num instrumento efetivo e norteador para o planejamento da atenção hematológica e hemoterápica nos estados e Distrito Federal e, deve estar articulado com as diretrizes da Política Nacional de Sangue e Hemoderivados.

Os planos diretores regionais de sangue dos estados e do Distrito Federal devem conter uma descrição detalhada baseada em análise da situação de saúde da população. Esta análise da situação de saúde da população deve ter como base o levantamento do cenário existente e do que mais será necessário para assegurar a atenção adequada à saúde da população. Assim, deve-se realizar a análise situacional para definir metas a serem alcançadas em um determinado período. A partir daí, define-se as estratégias, ações e os recursos necessários para garantir a execução da Política de Sangue e Hemoderivados, sugerindo orientação dos investimentos estruturantes necessários a serem feitos pelas três esferas de governo, quando pertinente.

De acordo com o Decreto $n^{\circ} 3.990 / 2001$ em seu artigo $5^{\circ}$, compete aos estados e ao Distrito Federal, no âmbito do Sinasan, a gestão, a coordenação e a elaboração do plano diretor de sangue, componentes e hemoderivados, bem como promover, em articulação com o Ministério da Saúde, o acompa- 
nhamento e a avaliação do cumprimento das metas e das ações do Sinasan, tendo dentre suas atribuições: adequar, em articulação com os municípios, os parâmetros assistenciais do plano diretor estadual de sangue, componentes e hemoderivados, incluindo a assistência hemoterápica no estado; e, acompanhar e avaliar o cumprimento das metas estabelecidas no plano diretor estadual de sangue e hemoderivados. (BRASIL, 2001)

Em seu artigo $7^{\circ}$, o decreto refere que a construção do plano é conduzida pela hemorrede estadual juntamente com vigilância sanitária, vigilância epidemiológica, planejamento e controle e avaliação e atores que são considerados relevantes em cada plano. (BRASIL, 2001) Entretanto, na prática, garantir que os diferentes segmentos da sociedade participem nas atividades de planejamento, execução e acompanhamento da Política de Sangue e Hemoderivados é um grande desafio. O plano deve ser homologado pelo Conselho Estadual de Saúde e aprovado pelo Ministério da Saúde, segundo parecer técnico. (BRASIL, 2001)

\section{II] Por que uma plenária para socialização dos produtos finais do curso?}

Independente da obrigatoriedade da elaboração do Plano Diretor pelos estados e Distrito Federal, é desejável que todos os gestores conheçam a sua realidade, se dediquem a reduzir as desigualdades e não meçam esforços para melhorar a qualidade de vida da população.

A atividade de elaborar e/ou revisar o Plano Diretor de Sangue e Hemoderivados é uma oportunidade para estabelecer um processo permanente de construir políticas, avaliar ações e corrigir rumos. Além de servir para incentivar: (i) capacitação de gestores e equipes locais; (ii) sistematização e revisão de normas e portarias e; (iii) integração da política setorial de sangue e hemoderivados, com os orçamentos anuais Lei Orçamentária Anual (LOA) e Plano Plurianual (PPA) bem como com o Plano Estadual de Saúde, o Plano Diretor de Regionalização da saúde (PDR) e a Programação Pactuada Integrada (PPI).

Democratizar e explicitar as decisões são ações fundamentais para que todos se comprometam com processo de construção do Sistema de Sangue e Hemoderivados, tornando a definição de políticas um trabalho compartilhado e fazendo com que todos, sintam-se responsáveis e responsabilizados com o sucesso desta política. 


\section{III] Qual a estrutura de um Plano Diretor? Quais orientações podem ser consideradas para sua elaboração?}

O processo de planejamento deve aproximar a teoria da prática, num movimento dialógico de construção (TEIXEIRA, 2010), que utiliza o enfoque estratégico situacional e considera a participação social na definição, implementação e avaliação das ações. Nesse sentido, a Teixeira (2010) propõe movimentos para o processo de elaboração de um plano, o qual deve partir da construção de uma proposta de planejamento integrado e da análise de situação de saúde.

Os movimentos para este processo de construção compartilhada devem considerar as demandas e recomendações das conferências de saúde, bem como os problemas "discutidos e chancelados" nas reuniões/oficinas realizadas com distintos atores - conselheiros, gestores, técnicos, etc., para, então, definir linhas de ação, compromissos, objetivos e ações, considerando, portanto, a viabilidade financeira-orçamentária. (TEIXEIRA, 2010)

A partir dessa compreensão, sugere-se a seguir a estrutura ${ }^{2}$ de um plano diretor estadual, com respectivas orientações para a sua elaboração. Este plano deve ter no mínimo: a) Elementos pré-textuais; b) Elementos textuais: introdução/apresentação; análise da situação da saúde; módulos operacionais; diretrizes, objetivos e metas; monitoramento e avaliação do plano diretor; planejamento de investimentos; c) Elementos pós-textuais.

a) Elementos pré-textuais:

- Capa: logo e nome da instituição, nome do serviço, título do plano, local, data;

- Contracapa: diretores, gerentes, coordenadores, equipe de elaboração/colaboradores;

- Lista de siglas: siglas utilizadas no texto, colocadas por extenso;

2 A proposta de estrutura de Plano Diretor para as Hemorredes foi elaborada a partir de um trabalho conjunto da equipe de coordenação e da equipe de elaboração do Planeja Sangue. 
- Lista de tabelas e/ou gráficos e/ou mapas: identificação das tabelas, gráficos, mapas e figuras na sequência de apresentação ao longo do plano;

- Sumário: capítulos, paginação.

b) Elementos textuais:

- Apresentação: resgatar os princípios e diretrizes que norteiam a Política do Sangue no estado, apresentar a importância do processo de planejamento e da elaboração do plano, referir o Decreto $n^{\circ} 3990 / 2001$, descrever a metodologia para a elaboração do plano fazendo menção às atividades realizadas a partir da participação de profissionais e representantes de diferentes espaços da configuração institucional do estado no curso "Planeja Sangue";

- Análise da situação de saúde: o consolidado da análise situacional deve considerar a divisão regional segundo o Plano Diretor Estadual de Saúde. Deve conter descrição e análise do(a):

- Perfil demográfico e epidemiológico por região de saúde: extensão territorial, divisão regional e distâncias entre as regiões, densidade demográfica, população - concentração e características relevantes, projeções de crescimento, fecundidade, natalidade, envelhecimento, expectativa de vida, dentre outros;

- Estrutura e organização dos serviços de saúde no sus estadual: cenário da capacidade instalada, condições de infraestrutura por região, disposição da rede de atenção estadual - unidades e serviços hospitalares por nível de complexidade de leitos conforme os Parâmetros SUS (BRASIL, 2015) anteriormente recomendados pela Portaria $\mathrm{n}^{\circ} 1.101$ de junho de 2002 , atenção especializada e atenção básica, urgência e emergência, configuração dos serviços públicos e privados considerando a atenção hematológica e a distribuição dos serviços hemoterápicos nas regiões do estado; 
- Características da Hemorrede Estadual: 1. Histórico e objetivos da Hemorrede estadual; 2. Gestão da Hemorrede estadual: descrever a hierarquia do sistema, a natureza jurídica da Hemorrede, a relação entre os integrantes do sistema e a forma de contratualização com os serviços, a governança do sistema, bem como, a configuração dos processos de gestão e qualificação das pessoas - tipos de vínculo, perfil da força de trabalho, perfil de formação, da qualidade, de gestão dos recursos, de materiais e serviços, de infraestrutura física, de equipamentos e informática, sobre a existência de planos de contingência, gerenciamento de resíduos, biossegurança, logística, marketing, sistemas de informação (SUS e próprios da Hemorrede) ensino e pesquisa, atenção hemoterápica ciclo do sangue - do doador ao receptor - e hematológica (ciclo do paciente) e outros; 3. Análise da disposição/oferta dos serviços e ações para a atenção hematológica e hemoterápica no estado: elaborar texto de análise considerando as informações levantadas em relação aos parâmetros da atenção hemoterápica utilizados, devendo-se adotar tabelas, gráficos e matrizes (planilhas). Para o dimensionamento da atenção hematológica, recomenda-se ressaltar ainda a importância de se realizar análise conjunta dos parâmetros populacionais, de infraestrutura e de assistência levantados, inclusive considerando, a partir de tal análise, quais as pactuações e articulações necessárias com os demais pontos de atenção da rede, com os gestores das secretarias estaduais, com os gestores dos serviços de hematologia e hemoterapia, visando, contudo, à melhoria e aperfeiçoamento da oferta de ações e serviços da atenção hematológica. Descrever a análise da situação sanitária dos serviços, - destacar os que estão adequados e as não conformidades -, mencionar os resultados de avaliação do Programa Nacional de Qualificação da Hemorrede, resultados dos testes de proficiência dos programas de avaliação externa da qualidade e os resultados das inspeções sanitárias; descrever a necessidade de adequações da estrutura, com implantações de novas unidades assisten- 
ciais ou transformações das existentes e, nos locais em que não existir unidades fixas de coleta, avaliar a realização de coletas externas. Analisar a distribuição de oferta e da necessidade regionalizada, considerando as ações e atividades ${ }^{3}$ a partir do cálculo das necessidades com base nos parâmetros - considerar coleta, processamento, sorologia e imuno-hematologia, laboratório NAT, coleta de sangue e perfil das doações - considerar a racionalização e o aperfeiçoamento das redes de produção de hemocomponentes sem prejuízo à descentralização e hierarquização da assistência, considerar a otimização de recursos necessários para implantação ou adequação de um serviço, garantindo uma produção mínima que justifique os recursos de investimento que necessariamente serão mobilizados para sua implantação. Sugere-se comparar a realidade apresentada com os parâmetros e o índice populacional, deficiências de unidades hemoterápicas, distância e demais necessidades apresentadas.

- Módulos operacionais4: a partir da análise de situação de saúde, identificação e priorização de problemas e das intervenções sobre o estado de saúde e sobre a organização do sistema, consideradas a divisão regional de saúde, deve-se adotar a definição de objetivos e dos planos ou módulos operacionais, os quais devem ser detalhados pelos objetivos específicos, diretrizes, metas, ações, responsáveis, prazos e indicadores. Tais aspectos podem ser organizados nos seguintes recortes indicando cada plano ou módulo operacional: (1) Gestão do Sistema; (2) Linhas de Atenção à Saúde - Fluxo do Paciente (3) Produção e Distribuição de Sangue - Ciclo do Sangue;

3 Coleta; Processamento; Sorologia e Imuno-hematologia do doador; Laboratório NAT; Perfil das doações de sangue, considerando a cobertura populacional; Fontes de Recursos.

4 A proposta de "modularização" do produto do planejamento consiste no entendimento do plano como "modular", composto de módulos operacionais que sintetizam os elementos do processo de trabalho previsto (objetivos, atividades, produtos e resultados, responsáveis, participantes, prazos e recursos), flexibilizando a organização e facilitando a participação de distintos sujeitos sociais, bem como um ordenamento espaço-temporal em função do desenho estratégico. (TEIXEIRA, 2001, p. 8) 
(4) Aquisição e Distribuição de Hemoderivados; (5) Rede de Serviços - Infraestrutura Física e de Equipamentos; (6) Sistema de Informação e Infraestrutura de Informática; (7) Gestão do Trabalho e a Qualificação de Recursos Humanos; (8) Risco Epidemiológico e Sanitário; (9) Investimentos em Hemoterapia e Hematologia.

Quadro 4 - Exemplo/modelo para elaboração de módulo operacional

\begin{tabular}{|l|l|}
\hline Módulo Operacional I - GESTÃo DA HEMORREDE NO SUS ESTADUAL \\
\hline $\begin{array}{l}\text { Diretriz l - Fortalecer a Gestão da Hemorrede Estadual no âmbito do Sistema Único de Saúde e no contexto da } \\
\text { regionalização }\end{array}$ \\
\hline Objetivo 1.1 - Aprimorar a Gestão da Hemorrede estadual no âmbito do Sistema Único de Saúde \\
\hline Indicador de monitoramento: \\
\hline Responsáveis: & Projeto/ \\
\hline Meta: & Atividade PPA \\
\hline Ações & \\
\hline Implementação da gestão por competências e modernização... & \\
\hline Fortalecimento das ações...
\end{tabular}

Fonte: Salvador (2014).

- Monitoramento e avaliação do plano diretor: para acompanhar e avaliar o cumprimento das metas estabelecidas nos planos diretores deve-se definir um conjunto de indicadores, determinando claramente as fontes de obtenção e o método de cálculo, os quais serão monitorados e avaliados constantemente. É fundamental estabelecer um pacto de indicadores referente ao ciclo de sangue e a cobertura da atenção hemoterápica e hematológica. O acompanhamento e avaliação do processo de execução das atividades propostas deve, por sua vez, ser desenvolvido a partir da montagem de um conjunto de mecanismos que envolvem alguns tipos de controle, dentre eles, o controle dos procedimentos burocráticos utilizados normalmente na administração pública, os quais devem obedecer as leis e normas vigentes; o controle gerencial que implica no estabelecimento de mecanismos que permitam o alcance da chamada "eficiência alocativa" (produtividade ao menor custo); o controle de qualidade voltado à garantir a eficácia técnica e a qualidade das ações executadas, baseando-se 
na aplicação das normas existentes e da elaboração e aplicação de normas que impliquem na utilização do conhecimento científico disponível e das tecnologias mais adequadas; e, o controle social que se refere ao acompanhamento e avaliação da gestão e execução das políticas e das atividades, sendo realizado pelos órgãos colegiados previstos na legislação do SUS, isto é, os Conselhos de Saúde. (TEIXEIRA, 2001, p. 23-24) A análise sistemática dos dados e informações disponíveis será fundamental para apoiar as instâncias de decisão. É de fundamental importância (1) verificar a execução das metas previstas no Plano Diretor e avaliar se as ações desenvolvidas pela Hemorrede estão beneficiando os cidadãos e se melhoram a saúde da população; (2) acompanhar os indicadores pactuados; (3) verificar o cumprimento da Lei Complementar $n^{\circ} 141 / 2012$ por parte dos estados e municípios; e (4) verificar a necessidade de reorientação estratégica das ações frente a novos cenários, sejam políticos, econômicos, sociais, epidemiológicos ou de catástrofes. Nos estados e no Distrito Federal o monitoramento e avaliação do Plano Diretor serão executados pela Câmara de Assessoramento da Política de Sangue e Hemoderivados a qual cuidará do acompanhamento de diretrizes e metas a serem desdobradas em programas e/ou projetos.

- Planejamento de investimentos ou viabilidade financeiro-orçamentária do Plano Diretor Estadual de Saúde: demonstrar onde estão alocados os recursos orçamentários que conferem suporte financeiro à execução das ações estratégicas propostas para o alcance das metas e resultados esperados para o período. Deve-se apresentar os gastos com a atenção hematológica e hemoterápica. Recuperar o que já está assegurado como fontes de recursos que financiam o serviço. Desenvolver a análise dos investimentos previstos e realizados na estruturação da rede considerando o Plano Plurianual (PPA) vigente. De acordo com o Decreto $n^{\circ} 3990 / 2001$ o financiamento para a execução dos planos, acontecerá com recursos provenientes da União, da participação dos Estados, do Distrito Federal e dos municípios, de acordo com a legislação vigente. O repasse dos recursos da União para a área de sangue e hemoderivados está condicionado à aprova- 
ção do plano diretor estadual de sangue e hemoderivados. Sugere-se a previsão dos recursos orçamentários necessários para alcançar as metas previstas no Plano de Investimentos. O mesmo deve ser planejado para quatro anos, em conformidade com o Plano Plurianual (PPA). O Plano Anual de Investimento deve tomar como base o planejamento elaborado no Plano Plurianual. O mesmo deverá trazer informações referentes aos recursos orçamentários necessários para o alcance das metas pactuadas e previstas para área de Hematologia e Hemoterapia, no que se refere aos investimentos a serem realizados no exercício de vigência da Lei Orçamentária Anual. No Plano Anual de Investimentos ficam evidenciadas as metas que devem ser cumpridas, em que prazos e que ações e orçamento serão necessários para este fim.

c) Elementos pós-textuais:

- Apêndices: apresentação de gráficos, tabelas, figuras e/ou mapas;

- Anexos: documentos parciais ou na íntegra.

\section{Referências}

AGÊNCIA NACIONAL DE VIGILÂNCIA SANITÁRIA. Resolução RDC n 151, de 21 de agosto de 2001. Aprova o Regulamento Técnico sobre Níveis de Complexidade dos Serviços de Hemoterapia, que consta como anexo. Diário Oficial [da] República Federativa do Brasil, Poder Executivo, Brasília, DF, 22 ago. 2001. Seção 1, p. 29.

BERBEL, N. A. N. A problematização e a aprendizagem baseada em problemas: diferentes termos ou diferentes caminhos? Interface: Comunicação, Saúde e Educação, Botucatu, v. 2, n. 2, p. 139-154, fev. 1998.

BRASIL. Decreto $\mathrm{n}^{\circ} 3.990$, de 30 de outubro de 2001. Regulamenta o art. 26 da Lei $n^{\circ} 10.205$, de 21 de março de 2001, que dispõe sobre a coleta, processamento, estocagem, distribuição e aplicação do sangue, seus componentes e derivados, estabelece o ordenamento institucional indispensável à execução adequada dessas atividades. Diário Oficial [da] República Federativa do Brasil, Poder Executivo, Brasília, DF, 31 out. 2001. Seção 1, p. 1. 
BRASIL. Ministério da Saúde. Portaria $n^{\circ}$ 1.631, de $1^{\circ}$ de outubro de 2015. Aprova critérios e parâmetros para o planejamento e programação de ações e serviços de saúde no âmbito do SUS. Diário Oficial [da] República Federativa do Brasil, Brasília, DF, 2 out. 2015. Seção 1, p. 38.

JORBA, J.; SANMARTÍ, N. A função pedagógica da avaliação. In: BALLESTER, M. et al. Avaliação como apoio à aprendizagem. Porto Alegre: Artmed, 2003. p. 23-45.

MATUS, C. Teoria da ação e teoria do planejamento. In: MATUS, C. Política, planejamento \& governo. Brasília, DF: Ipea, 1996. p. 81-98.

SALVADOR (BA). Prefeitura Municipal. Secretaria Municipal de Saúde. Plano municipal de saúde 2014-2017. Salvador, 2014.

SANTOS, C. M. et al. Estudo de caso. In: SOUZA, M. K. B. et al. (Org.). Planeja Sangue: cursos em planejamento e gestão de sistema e serviços de saúde: guia para estudos. [S.1.]: Salvador, 2015. p. 127-132.

SOUZA, M. K. B. et al. (Org.). Planeja Sangue: cursos em planejamento e gestão de sistema e serviços de saúde: guia para estudos. [S.1.]: Salvador, 2015.

TEIXEIRA, C. F. Planejamento municipal em saúde. Salvador: Instituto de Saúde Coletiva da Universidade Federal da Bahia, 2001.

TEIXEIRA, C. F. (Org.). Planejamento em saúde: conceitos, métodos e experiências. Salvador: Edufba, 2010.

UNIVERSIDADE FEDERAL DA BAHIA. Moodle. Salvador, [2015]. Disponível em: <www.novomoodle.ufba.br >. Acesso em: 1 set. 2015. 